Article

\title{
Fostering Alliances with Customers for the Sustainable Product Creation
}

\author{
Marjan Leber ${ }^{1}$, Andrea Ivanišević ${ }^{2}$, Jelena Borocki ${ }^{2}$, Mladen Radišić ${ }^{2, *}$ (i) \\ and Beata Ślusarczyk ${ }^{3,4}$ \\ 1 Faculty of Mechanical Engineering, University of Maribor, 2000 Maribor, Republic of Serbia; \\ marjan.leber@um.si \\ 2 Department of Industrial Engineering and Management, Faculty of Technical Sciences, University of Novi \\ Sad, 21000 Novi Sad, Republic of Serbia; andreai@uns.ac.rs (A.I.); borocki@uns.ac.rs (J.B.) \\ 3 The Management Faculty, Czestochowa University of Technology, al. Armii Krajowej 19 B, 42-201 \\ Czestochowa, Poland; beata.slusarczyk@wz.pcz.pl \\ 4 Faculty of Economic Sciences and IT, North-West University, Vaal Triangle Campus, P.O. Box 1174, \\ Vanderbijlpark 1900, South Africa \\ * Correspondence: mladenr@uns.ac.rs; Tel.: +381-64-144-7048
}

Received: 25 June 2018; Accepted: 28 August 2018; Published: 7 September 2018

check for updates

\begin{abstract}
Our paper analyzes close collaboration between a manufacturer of domestic appliances and consumer electronics and its customers. It reflects on the inclusion of open innovation by users that is presented in the paper on the case of the development of the refrigerator door handle, with an emphasis on design and functionality. The main research question we wanted to answer was whether a buyer (customer/consumer) might actively participate in the process of a new product development. It was interesting to test it in a highly dynamic industry setup since white goods are becoming an integral part of consumers' life style and not just a mere home appliances used for routine housekeeping tasks. Research sample includes 146 respondents. We applied the conjoint analysis and quality function deployment (QFD) in order to test and understand how customers perceive the different attributes of a new product development process.
\end{abstract}

Keywords: customer; sustainable product development; open innovation; conjoint analysis; quality function development

\section{Introduction}

The customer has always been and will be a priority in the development of a new product, where it is first necessary to understand his/her requirements and expectations. In the paper, we will present the phases in the development cycle and the possibilities of integrating the customer from the phase of finding ideas, because only thus we obtain very important information, based on which we can develop a successful product. From a customer's point of view, it is necessary to systematically approach quality, with the development of quality functions as an important factor contributing to customer satisfaction. The key to success is teamwork, coordinated work in linking ideas and a deep understanding of customer's wishes and needs, which is also the primary purpose of open innovation. This promotes creativity, which ultimately gives added value to the product. Social networks have a great role to play in the modern world as they enable interactions between customers and exchange of opinions and experiences. In the future, the World Wide Web is likely to have an even greater impact on things than it does today. Internet of Things will become part of everyday life, as well as communication between products and people.

Implementation of well-defined inclusion process of customers while defining a new product could equip companies with higher market success chances. This paper focuses on the case from 
white goods industry. The paper aims to present statistical analysis of the main observed variables that determine customers' inclusion in the process. Presented results in this paper might be of use for business and management researchers and practitioners. This paper systematically presents the conducted analysis on the sample of 146 respondents with a special focus on:

- new product development on the global market (Section 2),

- inclusion of a customer in the development process (Section 3),

- needs-based quality planning (Section 4),

- household appliances development process (Section 5),

- research results and discussion (Sections 6 and 7), and

- concluding remarks (Section 8).

Sections 2 and 3 reflect mainly on theoretical background and literature review, while Section 4 introduces the methods used in the research. Data sample and research methodology are given within Section 5, followed by extensive results presentation (Section 6) and further discussion (Section 7). At the end, conclusions and future research directions are given in Section 8.

\section{New Product Development on the Global Market}

Developed markets show their rigidity, they are becoming more and more intolerant, crises are repeated in faster cycles, customers are becoming more demanding, we are living in time of rapid technological advances, competition and raw material prices, etc. Therefore, the question arises, how to run a business production system in the direction of its success and long-term growth. One of the ways is to adapt to the requirements of customers and to change production processes, and not just their optimization.

In the last century they people were struggling with the problem of how to make things, while today we are thinking about how to make the product with a lowest possible cost, to sell it successfully, to maximize its profits and to satisfy the customer at the same time [1]. In particular, the latter is the starting point for a good reputation of the company. Nowadays, it is no longer a problem to produce, but to sell, which clearly illustrates the limits of capitalism itself.

Given the specificity of the business environment, the processes in the company must also be adapted; one such process is the development of the product. In the product development process, it is necessary to prudently take into account the maximum of the key factors that make up the mosaic of the development process. Each company has a vision that in addition to the mentioned environmental influences primarily depends on internal activities, employees, individual competences and knowledge, strategy, technology, infrastructure, etc. The strategy determines the direction of the company in its environment and coordinates all the necessary resources for successful introduction of the new product on the market. Most of the time, managers do not have the time, they sometimes even lack experience in finding new ideas; therefore, ideas for development come from different employees inside or outside of the company; the management only encourages this and determines how to achieve the goals set [2].

Today's advanced product development concepts put various organizational process tools (JIT (Just in Time), TQM (Total Quality Management), Kaizen, QFD, Target Costing, Open Innovation, etc.) to the forefront. Upon successful development it is necessary to include advanced technologies, the continued use of computer tools CAD-CAM is already a standard. These advanced technologies are one of the tools of the Industry 4.0 concept, which is the result of changes taking place in the global economy. The principles and technologies of Industry 4.0 can influence how products are manufactured, as well as customers' perception of the value of products. For example, products may be designed to contain a unique electronic identification in order to track the product's life cycle. This enables the collection of data on usage, which in turn can help companies to understand patterns of consumption, improve the customization of products, and enhance the service aspects of products, such as maintenance services, upgrade services, and so on. Additionally, connections 
between machines, devices, and supply chain tiers, by shared information, create the possibility to quickly modify production and purchase order priorities (due to customers' requirements), monitor and control performance of production lines, track deliveries and improve logistics routes [3].

The Fourth Industrial Revolution stimulates open connection, that is, open innovation, between technology and the market, while IT spreads across primary, secondary, and tertiary industries, and dynamic new combinations between technology, the market, and society are formed. In other words, as the Fourth Industrial Revolution is under way, the width and speed of open innovation, and the emergence of new combination business models exponentially increase [4].

According to Pachura (2017), models for innovations development and implementation within organizations depend on the fact that allows innovative projects to be kicked-off. Achieving positive results based on innovation corresponds with change as a phenomenon which is in core of modern enterprise and there are numerous activities contributing in this respect, where Pachura highlights the following, among others:

- going beyond the traditional organizational framework of the space of innovation,

- organizing new technical and organizational feeds,

- extending the subject and object structure of innovations,

- searching for non-traditional sources of new knowledge generation [5].

The process of integrating sustainability concept into business models of companies has a huge impact on their business and therefore on their competitiveness [6]. Sustainability, integrated in the process of developing a new product (NPD), represents one of the many changes in modern business environments. Nevertheless, the potential impact of sustainability on NPD does not affect all companies in the same manner, since it depends to a certain extent on the ability of a company to provide additional knowledge and information from all relevant stakeholders, and especially its customers [7].

Certain stages of development of a new product require the application of various tools that focus on particular aspects of the process. QFD is one of the tools that is very commonly used in different phases of the NPD process, as well as conjoint analysis, AHP process, benchmarking, fuzzy analysis, and some other analyses [8-11]. All these analyzes in a systematic way try to identify the potential problems of the NPD process and to reduce the uncertainty and risk that the placement of the new product will carry Conjoint analysis and QFD tools aim to help the companies using them to incorporate customer preferences as well as their expectations into the characteristics of the new product, which should influence the reduction of potential risk and uncertainty [12].

The product is a basic element of production-oriented enterprises. "It is each and every thing that can be offered to the market to initiate attention, acquisition, use or consumption and that can satisfy the customer's need or desire" [13].

New products are the driving force of progress, they create enthusiasm among consumers, dedication and a better climate in the company; in every industry, their development is crucial, as the company ensures continuous growth of its industry as well as the economy [14].

The reasons for which innovation and product development take place are the following [14]:

- Shorter product life cycles-boosting innovation

- Personalization of customer needs

- Rapid market changes due to globalization

- Creation of new business forms and more complex, fast-changing technologies [14]

New products are development factors that achieve the goals of a society for a better quality of life; they precisely coincide with the goals of the society that ensures the business systems existence.

In the future, a huge number $(80 \%$ of products that will be available in 2020 , have not been invented yet [15]) of products will be developed and they will be brand new products; on the other hand, they are only about improving existing products, which, despite the same or somewhat modified mode of operation, continuously satisfy consumers. Whether the individual, or products of broader 
production, the fact is that the need to keep them is constantly emerging. If we take the example of a car, we can say that this is a product that will be kept on the market for a very long time due to its practicality. Although open innovation appears to be related to a greater ease in imitating innovations carried out elsewhere, while decreasing incentives to innovate. However, many studies show that open innovation activities also have positive effects on the innovation of totally new products in the firms' market or even in the world, so that, in the so-called open innovation era, companies often have both innovated and imitated products in their portfolio $[15,16]$.

Its main component, the engine, has been working on the same principle for over a century (excluding various Wankel and other versions that are not so commonly used), so we could say that the process of developing the engine is almost no longer needed, yet this process never stops in order to maintain the competitive position of manufacturers. The implementation of the development function is what leads to lower fuel consumption, quieter engine operation, better sealing of valves, more precise fuel injection, improved materials, etc. or as in an example of a refrigerator, with quieter performance, improved insulation, addition of new practical features, a better look, less energy consumption, etc. Therefore, the principle of operation remains the same, but the development has created added value to the new products and increased customer's enthusiasm.

The new product development process (NPD) in the company is a targeted process, a project that requires financial investments, a different level of knowledge and interdisciplinary approach. NPD projects must be completed within the minimum time with minimum costs and maximum quality. To achieve the objectives of the project it is necessary to determine the input strategies, team leaders as well as project plan, execution deadlines and costs, implementing appropriate organizational structure that ensures minimal formalities, hierarchies and plenty of verbal and written communication, etc. [17]. The process of new product development starts with the generation of a new idea. This may arise from creative intuition, or from an insightful evaluation of deficiencies and failures in existing products. The idea may also arise from user/consumer feedback. Thus, it shows the significant role of clients in creating new products or improving existing ones. NPD ability of explorative products involves new technology knowledge and the newest product development for customers as well as develops new ideas with features with different possibility will cause differentiation in products [18-20].

When the need for a product arises, we also get new ideas, we begin to make plans; what follows is the product development (devising, designing, elaboration) and the result is a sample product. If this is successful, the next step is production planning and the production itself (materials, parts, equipment are needed). The product continues its journey to the store, then into use, and finally to removal [1].

Advanced concepts in product development constitute the so-called systematic process and the concept of "Stage-Gate" (Figure 1), which has become a widely used method for devising, developing and introducing new products in the industry today. The concept identifies activities to bring a product to the customer, providing good control and fewer mistakes, linking different areas of the company. The model divides the whole process into individual stages, among which there are control points called the gate, where decisions are made for a possible continuation or shutdown of the process [21,22]. 


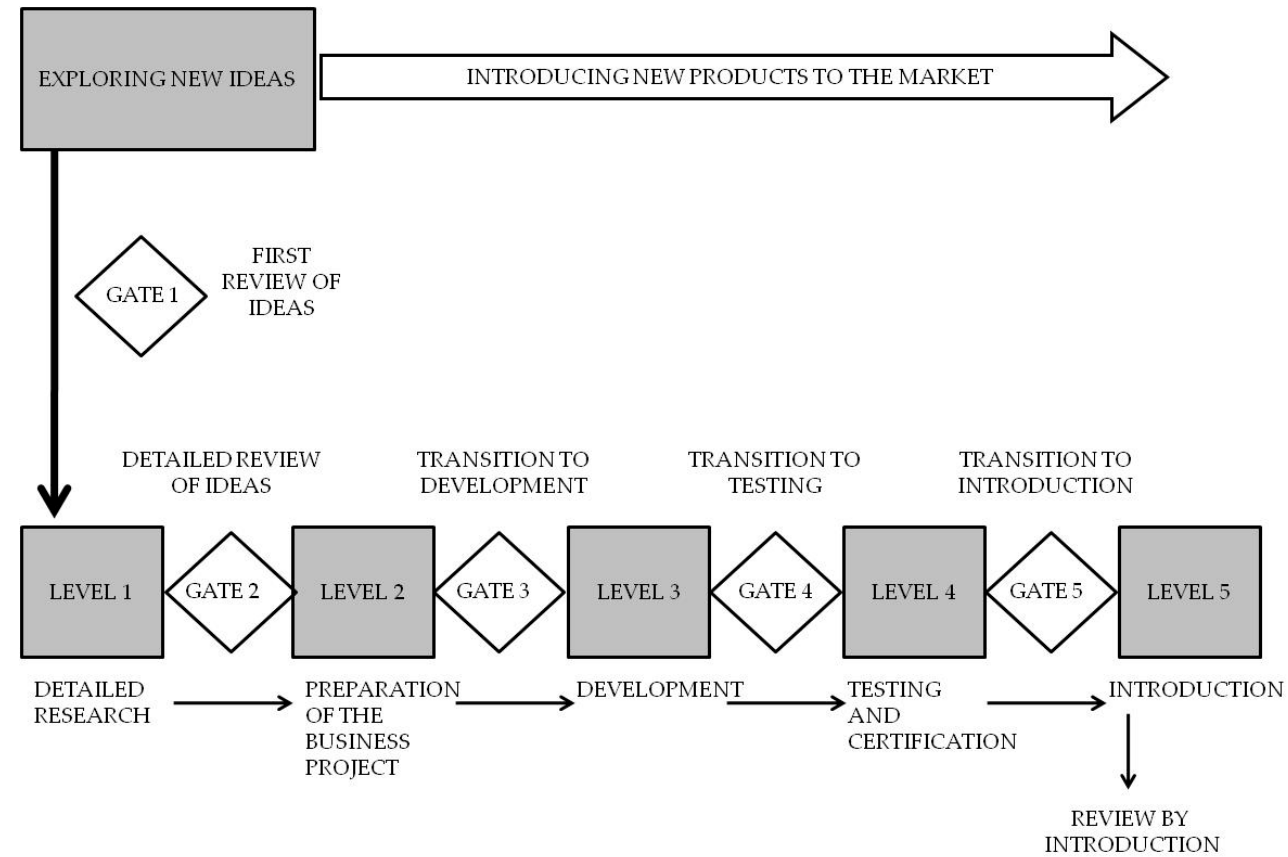

Figure 1. Graphical illustration of model Stage—Gate as defined in [22].

\section{Development Process and a Customer}

Cooper [23] is of the opinion that the inclusion of the buyer in the early stages is vital for the success of the project. At this stage there is a lot of abstract thinking, which can be greatly contributed by potential buyers. Gruner and Homburg [24] agree with this idea, arguing that a high level of customer involvement makes a significant contribution to the new product. Customers are included in the development of well-known focus groups and leading users with whom they develop and narrow down the development concept. Very important role in the modern era is the World Wide Web, which enables customer-company as well as customer-buyer interaction. Verona and Prandelli [25] have found that the World Wide Web has greatly changed the value of co-creation. By using the Internet, the costs that arise when the information is obtained through the traditional route have been greatly reduced. In addition to high costs, traditional methods also have shortcomings in terms of limited customer-company interactions.

The conceptual phase is followed by the development phase of the product with all the corresponding functions. In the concept development phase, companies can share the concept with customers and actively follow their ideas and proposals, according to Grewal et al. [26]. The presence of a customer in the early stages of development can reduce the time and costs reducing the risk of failure at the same time, as we basically do not hide anything from customers.

The inclusion of the buyer during the commercialization and launch phase of the market presents the most risk and potential losses, as it is related to advertising costs. The last stage of development is the launch of the product on the market. At this stage, we focus on the opportunities and challenges of the value created. The involvement of the customer is often in different contexts and is quite popular in the modern world. Manufacturers of computer games gain much from users only after the product has been on the market for some time. Jeppesen and Molin [27] find that for many successful computer games, the majority of modifications come straight from the user's address. Creating a customer's awareness is critical to the success of any new product. This is usually achieved through the commercialization and creation of relations between the buyer-buyer and the company-buyer. A test of the product is required only when customers are aware and interested in a new product. By supporting interactions between customers and support, we can provide customers with better understanding of the product and its features. This is important because the experience of other users for a prospective buyer is worth more than the company's information. New technologies, such as 
social networks, are also important in the commercialization and launch phase. Some companies even have their own consumer groups, where they share experiences and opinions. This strengthens the relationship with their final customers, processes their experience for product improvements and saves money for advertising [28].

It is known that the customer's participation in the development significantly impacts both, the company and the buyers. The success of the company depends on the definition of the cooperation and subsequent implementation as we face positive responses and the possible risks that may arise from co-operation, according to Prahald and Ramaswamy [29].

\subsection{Positive Collaboration Responses}

The benefits of this kind of cooperation have been recognized fairly quickly all over the world. By successfully implementing and managing cooperation, the company can create two important sources of competitive advantage:

- Productivity is raised through increased efficiency.

- Improved efficiency due to higher product value, innovation and better matching with customer's needs.

Bowers et al. [30] recognize that collaboration increases productivity and efficiency due to minimization of costs, since employee input information is replaced with customer input information in the development or service process. Reducing costs is also linked to virtual questionnaire on buyer ideas, which reduces the need for information obtained through the traditional route. It is also less likely that the product will be unsuccessful, it gets marketed more quickly and gains continuous improvements and research of additional user information after launching on the market [31]. All these advantages can directly affect organizational performance, increase the efficiency of operations, improve the flow of product / service, customer satisfaction and, ultimately, profitability. In addition to the above, such products increase their efficiency through closer matching with customers and higher commercial potential, Fang and others emphasize [32]. The products have a higher added value with novelties, which, as Franke and others find, ref. [33] reflects or increases the commercial attractiveness of the product. The preferential match of such a product can in turn raise the positive attitude towards the product, increase the subsequent intentions to buy, prepare the customer for payment and spread a good word [34]. The buyer is also better acquainted with the challenges, costs and limitations of development that have been made in adjustments and settings and a better understanding of the product [35].

\subsection{Costs and Risks}

All the advantages listed above also include risks, which are related to costs. One of the major challenges that arise is the reduced control of strategic management and planning. Innovation is a vital function of management and plays a key role in business performance. Excessive influence of customers can cause friction within the company, so it is necessary to think carefully about the phase and how far the customer descends. Empowering the buyer at an early stage of development increases the risk of focusing on gradual innovation rather than on basic innovation [36]. In addition to reduced control, there may be confusion in the company. Here we mainly focus on the goals and interests of the decision makers (employees, shareholders, co-creators, etc.). An essential flexible communication and cooperation strategy for unpaid buyers, co-creators when compared to their employees has a high level of importance [37]. Interesting thinking of Bendapudi and Leon [38], says that the effect of co-creation is an asymmetrical process. It only works in a positive direction, with positive results and high expected quality and satisfaction. Otherwise, of course, we can get exactly the opposite effect from the one we want to achieve with the buyer's inclusion. On one hand, the company wants to satisfy the wishes of the buyer, but at the same time wants to be efficient and operate with as little cost as possible. 
The buyer, on the other hand, wants the product to their taste and good acceptance of the product. Cook [39] points out that, in some cases, customers can also turn to competition with the company that invited them to participate, which can hinder the company's reputation. Any attempt to limit the freedom of co-creators reduces their willingness to cooperate.

\section{Quality Planning According to the Needs of Customers}

In the initial phase of obtaining information in the process of developing a new product, we decided to apply the Conjoint method (CA), and the first step was to draw up a list of properties, to identify as many attributes as possible that we can use to influence the customer's requirements and wishes. Assuming all possible combinations of selected levels of attributes for creating appropriate cards (the product of all levels), we come to the realization that there are too many and the respondents would have a very difficult choice of simultaneous comparison of many levels on individual cards.

Although the SPSS program can form an orthogonal selection and eliminate the least suitable combinations, we have opted for a morphological matrix, where respondents themselves have chosen the desired level for each attribute. The solution of the combination of attributes in the form of the offered answers seemed more appropriate to us, because we found that a large number of attributes, their levels make the CA method ineffective; we wanted to prevent the similarity between card choices and more difficult decision making; that way we ensure more reliable data and limit the scope of the survey to just 5 minutes.

\subsection{Conjoint Analysis}

Conjoint analysis was originally developed in the early seventies with the help of mathematicians for the needs of Psychology, and today it is considered the standard market research technique. In everyday life, customers need to compromise when choosing the solutions because they cannot always get the best in the real world.

CA determines which features maximize customer's satisfaction, development engineers get a clear insight into the optimum properties of a future product or service, the loss of time that might be spent by developing unnecessary functions is reduced; at the same time, the method can be a good indirect advertising tool, as we obtain data on what could attract the customer. The goal of CA is therefore greater realism, and reality provides better data [40].

Of all CA methods, the $\mathrm{CBC}$ ( $\mathrm{CBC}$ - Choice Based Conjoint-the method is very suitable when the survey is carried out over the Internet. The more advanced method is the ACBC-Adaptive Choice Based Conjoint, in which the software formulates the following question on the basis of the previous one) method is most popular today. The $\mathrm{CBC}$ method is carried out in such way that the respondent decides and ranks the given options (cards) that contain several features, individual levels of characteristics combined (conjointly). Based on the ranking we add points (weights), and then we calculate the share of benefits for individual attribute levels so we get the preferences, which should be given the most attention.

The analysis can be carried out in four steps [40]:

1. List of properties and their levels-in this step, we carefully prepare a list of properties that form a product, and the level of individual properties.

2. Data collection-survey-implementation is carried out in the form of a survey using pre-prepared cards or using a computer program.

3. Calculation of the shares of benefits-means the statistical processing of the data obtained.

4. Market simulation-enables simulations with changing properties and measuring changes in preferences.

When looking for the importance of attributes and their levels by conjoint analysis, the following [40] must be performed:

1. Formulate the problem 
2. Identify alternative products

3. Decide on the method of data collection

4. Choose the method of conjoint analysis

5. Interpret the results

The first step for the researcher is to decide on the important attributes and the levels they intend to include in their research, while ensuring that the attributes are selected together with the management and experts who know the specifics of the industry and products. The number of attributes and levels determines the number of parameters and alternative products that the respondents will have to evaluate, so we make sure that this number is not too large. Assuming that all attributes have the same number of levels, the number of possible combinations is equal to $k^{m}$, where $k$ is the number of levels and $m$ is the number of attributes. We can use a two-factor approach to evaluate, in which two features are compared at the same time, or an approach that is more convenient in practice and requires simultaneous evaluation of all product features [41].

\subsection{Quality Function Development}

One of the methods of comprehensive quality assurance is the QFD method or the development of quality functions, which aims to functionally change products according to the requirements of the market and customer requirements; it is effective at an early stage of development, that is, the stage of conceptual design and product design. In 1966, the method was presented by Yoji Akao, and in 1972 it was practically used by Kobe Werft. This method was intensively and successfully used by Toyota, and its wider use in the Western world was achieved in 1991 or 1992 [42,43].

The QFD method, based on predefined customer requirements, recognizes the product characteristics, on which the fulfillment of all requirements depends, defines critical points of the product and its manufacturing process. The company's aim is to offer products that are of high quality, usable, economical and eco-friendly. All areas of the company, all employees from the different company's departments (at least marketing, development and production experts) work on improving the product characteristics, reducing costs, flow in the production process and work, as well as production efficiency.

The benefits of using the QFD method are as follows [43]:

It allows companies to increase competitive positioning and continuous quality improvement

- Group work is encouraged, the motivation of all employees is increased, timely communication is ensured, the cost of design and manufacturing decreases;

- Even at the early stages of product formation, potential irregularities can be detected;

- In a timely manner, we can determine whether our new product will be able to successfully compete with everything else on the market and come up with all the important insights about competing products;

- Easier definition and optimization of product costs, and manufacturing processes;

- The method is dynamic, so it can be used at different stages of design;

- Products meet the requirements and wishes of the customers to a greater extent;

QFD is initially used in the early stage of product development and later it spreads through all procedures of technical development, work preparation, production and quality assurance. At each stage we have to concentrate on focus and procedures that are relevant to the customer. QFD is implemented in four phases:

Phase 1 Product design: transfers the customer's requirements into product characteristics.

Phase 2 Assembling: transfers product characteristics into parts characteristics.

Phase 3 Process planning: transfers parts characteristics into production technology.

Phase 4 Production planning: transfers manufacturing technology into production instructions. 
In companies with functional organization the marketing department recognizes customer's needs very well, but it often happens that the information transferred to the development department is misunderstood and consequently mistakes are being made; that leads to the fact that in the end the production department has to deal with development problems. This problem is successfully eliminated by QFD method.

When using the QFD method, we form a typical matrix structure (the basis of the QFD method), often referred to as the "House of Quality", because the shape of the structure resembles a house. In translating the wishes of customers into technical specifications, innovative, realistic, objective solutions for their achievement are sought, and the process is trying to accomplish the highest performance.

\section{Household Appliances New Door Handle Development Process}

One of the methods of data collection can be a poll, which helps us to get the voice of the customer (VOC). The simplified "traditional" survey represents a source of our necessary findings, but the authors describe the process of obtaining key information from the customer as a very complex and systematic process called VOC marketing process.

This is a market research technique that represents the process of perceiving important details relating to the wishes, needs and expectations of customers or target groups and in general, it is the first step in the development of a new product. VOC is actually the way of giving the customer what they want the most from the manufacturer and at the same time avoiding the inconvenience that would deter customers. In addition to understanding the target groups and determining the factors that influence the formation of a new product VOC can be an important tool for innovation [43].

In the process of acquiring and defining the relevant information, we used the key points of reference (modified from [43]):

- Which product we focused on:

In this project we focused on the development and improvement of the handle for easier opening the refrigerator door.

- How the findings influenced the product and the process design for their production:

The VOC survey findings showed the preference of the buyer's wishes and at the same time the properties that are not important to them, which allows for the minimization of development costs. Through the individual characteristics we have adjusted process planning and product manufacturing. Market analysis has shown that companies tend to produce according to market demand and that demand for refrigerators, with adequately installed handle, so it makes sense to develop refurbished handle.

\subsection{The Aim of the Research and Used Methodology}

The product's and consequently, the company's performance is very much connected with the knowledge of the customer's needs, as buyers decide when to purchase the product in accordance with their own needs and expectations. These are constantly changing, so the process of identifying needs and expectations should be continuous. Customers always want to get better quality at the lowest possible price.

One of the aims of the research was to determine the importance that the refrigerator users give to the individual characteristics of the handle when assessing its quality as an important factor in purchasing decision making. The characteristics that determine the quality of the handle are associated with its shape and function, which should make the opening of the refrigerator door as easy as possible and contribute to the aesthetic appearance of the refrigerator. The significance of individual features may vary, depending on the demographic characteristics of users. Therefore, the aim of this research is to determine whether the significance of the features of the handle quality varies according to the 
gender and age of users. The information obtained in this part of the research we used in the "House of Quality" to develop a user-friendly handle.

The data necessary for this research was obtained through a web survey published and available free of charge on the SurveyMonkey tool. In this research, 146 respondents from Slovenia participated over the period of three months in mid-2017. For subsequent statistical processing of the collected data we used MS Excel and SPSS software tools.

\subsection{Questionnaire}

When creating a questionnaire, the rules of creation were adapted based on adequate literature $[44,45]$. Questions in the questionnaire were created so that the manufacturer receives information not only about the preferences of customers in comparison with the technical characteristics, but also in relation to certain elements of the design of the product itself. The questionnaire was divided into three parts. In the first part the respondents were asked about their gender and age. We offered three age groups (up to 20, 20 to 40 and over 40 years old). In addition, we have established their dominant hand (operant hand generally used for performing fine motor-skills tasks) and asked a few general questions, which determined the importance of knowing customer needs by manufacturers.

In the second part, respondents evaluated the usefulness of the handle function and the importance of individual characteristics. They expressed their views on usability on a five-point scale, where grade 1 was completely irrelevant and grade 5 very important. Using the same scale, they assessed the significance of individual aspects, which we identified together with employees in the development of cooling and freezing appliances. The features they assessed include: the handle material, the direction of the handle, the handle color, the length of the handle, the grip of the handle, the handle position, the shape of the handle, the inscription or the logo on the handle, the arrangement of the handle and the appropriate accessibility of the hand to the handle.

Internal validity assessment of the second group of questions was performed by using confirmatory factor analysis (CFA) within the R package lavaan [46,47]. Confirmatory parameters are treated with relative performance of the maximum likelihood (ML) and weighted least square mean and variance adjusted (WLSMV) estimator, which is suggested for models that consist of ordinal data, e.g., Likert type format [48]. Model fit evaluation had the following fit indices: comparative fit index (CFI), values above 0.90 are acceptable [49], Tucker-Lewis index, values above 0.90 are acceptable [49], and Weighted Root Mean Square Residual (WRMR index), values below 1.00 are acceptable [50]. The CFA analysis indicates that performed fit indices are very close to acceptable values: $\mathrm{CFI}=0.892, \mathrm{TLI}=0.857, \mathrm{i}$ WRMR $=1.125$, and based on this we conclude that internal validity assessment of the second group of questions is satisfactory. Standardized loading of the items on the latent factor range from 0.284 to 0.807 , with all loads being significant at $p<0.01$. Reliability by type of internal consistency for the second set of questions expressed by Cronbach $\alpha$ coefficient is sufficiently high: $\alpha=0.82$ [51].

In the third part, we introduced a morphological matrix with offered answers. Each answer, was supposed to emphasize the particular feature that the respondents would like the most the handle of their refrigerator. Individual levels in the survey of the features included are shown in Table 1.

Figure 2 is a part of the questionnaire in which images were added to facilitate the performance (for the illustration purposes), which illustrated the different operating modes of the handles for easier opening of the refrigerator door. 
Table 1. Attributes and individual level for the development of the handle.

\begin{tabular}{|c|c|c|c|c|}
\hline Attributes & \multicolumn{4}{|c|}{ Levels for Each Attribute } \\
\hline Material & Steel & Plastic & Aluminum & Hard rubber \\
\hline Direction of the Handle & Pull downwards & Pull upwards & Pull to the right & Pull to the left \\
\hline Color & $\begin{array}{l}\text { Compatible with } \\
\text { doors (one color) }\end{array}$ & $\begin{array}{l}\text { Not necessarily } \\
\text { compatible } \\
\text { (one color) }\end{array}$ & \multicolumn{2}{|c|}{ Multiple colors } \\
\hline Length of Handle & Shorter & Medium & \multicolumn{2}{|c|}{ Longer } \\
\hline Grip & Sliding & Slightly sliding & \multicolumn{2}{|c|}{ Non-sliding } \\
\hline Reception Place & $\begin{array}{c}\text { In several places of } \\
\text { the handle }\end{array}$ & \multicolumn{3}{|c|}{ In one place } \\
\hline Shape & Straight & \multicolumn{3}{|c|}{ Slightly rounded } \\
\hline Inscription or Logo & Yes & \multicolumn{3}{|c|}{ No } \\
\hline Positioning of the Handle & Vertical & \multicolumn{3}{|c|}{ Horizontal } \\
\hline $\begin{array}{l}\text { Adequate } \\
\text { Hand-to-Handle } \\
\text { Accessibility }\end{array}$ & $\begin{array}{l}\text { Just right for } \\
\text { smooth hand grip }\end{array}$ & \multicolumn{3}{|c|}{ Somewhat larger } \\
\hline
\end{tabular}

We were looking for answers to the following questions:

- Who are our customers:

Target groups are buyers who decide to buy a new refrigerator. In general, the handles are installed on the single door refrigerators of middle and upper-end price and particularly in fridge cabinets, on which the handle comes all the more evident.

- Definition of the target customer group:

The target group is in general, all potential customers who need a new refrigerator. When choosing a refrigerator, they focus primarily on the main features such as the price of the refrigerator, installation, the size, the power consumption, the look, etc., and additional mechanical and software functions are coming to the forefront (Fresh Zone, Zero Zone, Multy Flow air circulation system, water dispenser, automatic ice machine, quick freezing, adding voice commands, touch screens, installation of two compressors, etc.), among which it is a handle that makes it easy to open the doors, especially for the age group of the oldest and the youngest. When purchasing, it is important that combinations are made available to the buyer, which give them the ability to make more choices; additional functions must be well presented and should not excessively increase the basic prices.

- Ensuring the representativeness of the sample:

The selected sample of the survey was completely random, so the results can most probably be mapped from the sample to a larger population. Relevant statistical tests showed where the results can be generalized to the entire population. With brainstorming, the specific handle-related attributes that the customers wanted in their selection, all the main customer requirements (price, quality, safety, durability and reliability, easy opening, environmental friendliness) were considered self-explanatory and we did not include them in the survey, but later on we have certainly considered it.

\section{- Market analysis:}

The market is the place where businesses, customers, competitors and suppliers meet, and the success of companies on the market will depend primarily on understanding customers, while analyzing market developments (to examine competition, "our" sales versus demand for market, market shares, to evaluate the extent of possible sales in the upcoming year, to determine whether the product selling is still sensible, etc.) [52]. 

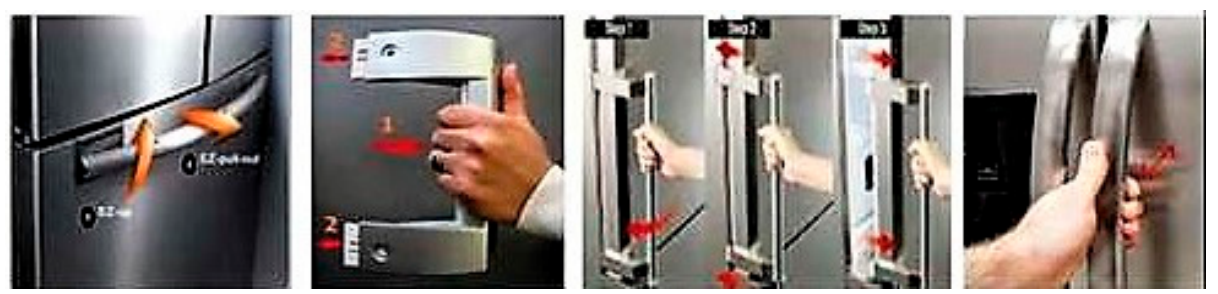

Figure 2. Illustrative visual identities of a door handle given in the questionnaire.

When creating a questionnaire, we had in mind the fact that it should reflect a concept of collaboration between stakeholders since alliances are an effective instrument for competition in global scale [53].

\section{Research Results}

The purpose of the analysis by group is to determine possible differences between women and men in the evaluation of some product features, which should be taken into consideration when drawing up the Houses of Quality; should the company produce two final products in the process of developing new products or consider the preferences of those groups that have more important role in purchasing decisions (similarly to age groups and different target group combinations). Statistical tests are obtained using the SPSS software tool. The results obtained from the sample were generalized at a characteristic level of 0.05 . If $p<0.05$, the results from the sample can be generalized to a population with $95 \%$ confidence and we conclude that there are statistically significant differences between the two variables.

146 participants responded to the request to complete the survey (sample size $\mathrm{N}=146$ ), of which 71 women $(48.6 \%)$ and 75 men (51.4\%). The sample of our study included almost the same number of women and men, i.e., 71 women $(48.6 \%)$ and 75 men $(51.4 \%)$. This fact reflects properly gender's role in purchases of large home appliances. This fact reflects properly gender's role in purchases of large home appliances, since the purchase of large home appliances show a large percentage of joint decisions, falling slightly behind those made unilaterally by men or women. Therefore, our conclusions are of use for both researchers and practitioners involved in finding out the basic behavior patterns of larger home appliances buyers. In the age group up to 20 years old, $10.9 \%$ were surveyed, $73.3 \%$ were in the group of 20 to 40 years old, and $15.8 \%$ in the group over 40 . The majority of respondents $(92.5 \%)$ were right-handed (dominant hand).

$60.3 \%$ of the respondents have the refrigerator door handle installed at home for easier opening. Next, the respondents evaluated (high average value of 4.363 on the five-point scale) the importance of the manufacturers' acknowledgment of customer's needs and requirements. Respondents also evaluated the usefulness of the door handle, namely $26.7 \%$ of them considered that the function of the handle, which allows us to easily open the refrigerator door is very important; the utility functions scored the average value of 3.7329 on the five-point scale.

Looking at statistical tests, we first assessed at the significance the users attributed to individual features. From the average values (five-point scale) for the entire sample, we found that the most important among the studied features is the distance of the handle from the door (3.596), followed by the direction of operation (3.514), the shape (3.411), the position of the handle (3.308) After this analysis, we get the first insight into the relevant features, which will have to be given the greatest attention in the development of the handle. These values are necessary for step 3 of the "House of Quality".

On the basis of the ANOVA test for more than two independent samples, two features (Length of handle and Grip) showed significant differences with respect to age target groups; older people (above 40) attribute greater importance to the two features; as for the other characteristics, there is no difference (Figure 3). Since $p<0.05$, it can be concluded that the differences were not random, but are the result of the age group's influence on their choice (Table 2). This means that the oldest participants have different preferences from the younger and the youngest. The manufacturer thus got an insight 
into the two most relevant characteristics to which they should give the greatest importance should they decide to produce handles that best meet the needs and expectations of the elderly.

The average values of the Grip features are shown in Figure 3.

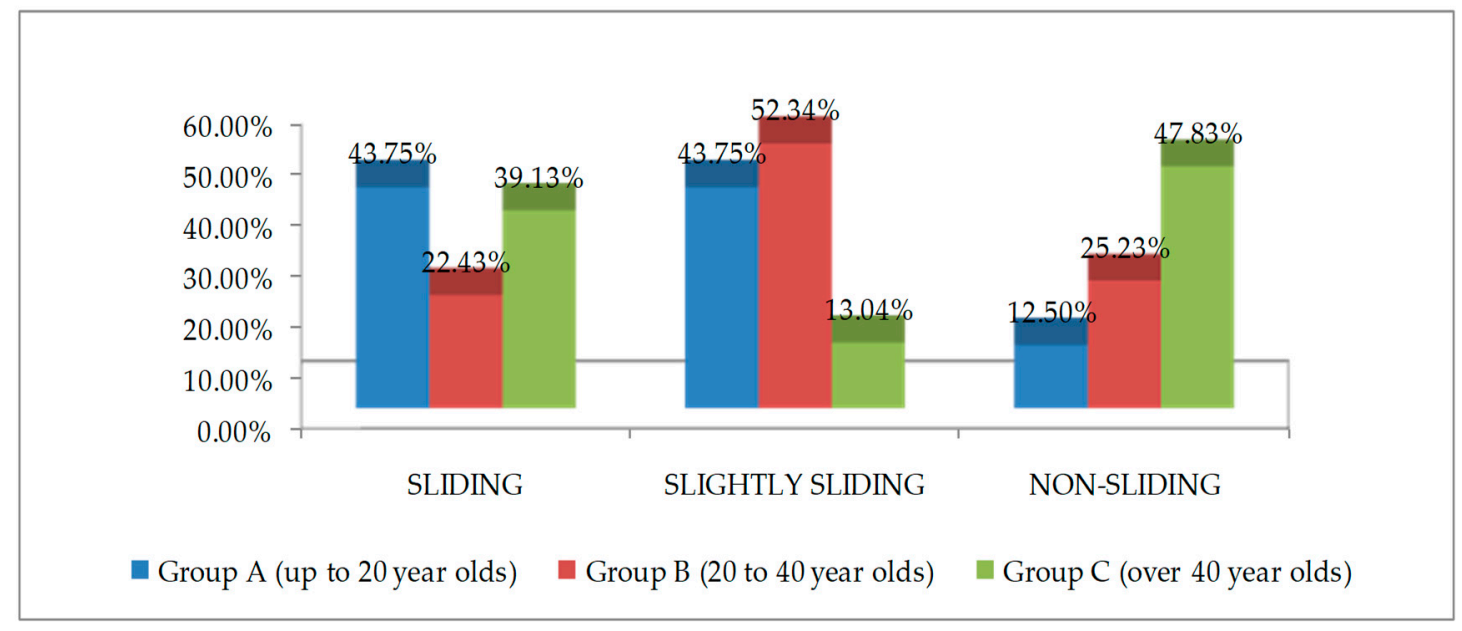

Figure 3. ANOVA test for the Grip feature.

Table 2. Chi-Square Test.

\begin{tabular}{cccc}
\hline & Value & df & Asymp.-Sig. (Two Sided) \\
\hline Pearson Chi Square & $15.137^{\text {a }}$ & 4 & 0.004 \\
Likelihood Ratio & 16.532 & 4 & 0.002 \\
Linear-by-Linear Association & 2.297 & 1 & 0.130 \\
No. of Valid Cases & 146 & & \\
\hline
\end{tabular}

a 2 cells $(22.22 \%)$ have expected countless 5 . The minimum expected count is 4.38 .

Considering the influence of the age target group on the choice of those levels for each feature that the respondents would most like to see on the handle of their refrigerator from the morphological matrix, differences were found only in the characteristics of the grip; namely a group of 20 to 40 years old give priority to the slightly sliding grip of the handle, while a group of over $40 \mathrm{~s}$ prefer non-sliding grip. The group of up to 20 years old excludes the possibility of non-sliding grips. On the basis of the ANOVA test and the value of $p<0.05$, it can be concluded that the differences were not random, but they come as a result of the influence of the age group on their choice.

Therefore, the manufacturer can make a handle that will satisfy each age target group by taking into account the relevant levels of the Grip characteristics for a particular age group.

With the exception of the Grip features, we cannot generalize the choice of other characteristics because of a small sample of the group of up to 20 and over 40 years of age, so we should be careful in interpreting the results. The findings should be used with caution, since it uses the pattern that is not random.

\section{Analysis Conclusions}

In age groups, we found that in regards of the choice of material, no age group wants a hard rubber handle; the direction of operation of the handle by pulling upwards doesn't suit them, they don't like the multicolor handle, which is all very similar to the result for groups with regards to gender; however, due to the value $p>0.05$ the results cannot be applied to the entire population.

We also created target groups with regard to the dominant hand, but the percentage of left-handed people in the survey was only $7.5 \%$ and that represents a small sample for the corresponding statistical tests. 
We can assume that in most of the features, both genders have chosen the same (the differences were only in the three of a total of 10 features); in addition, according to age (the difference was only in one feature) due to the smaller number of versions of the new product, the job for the manufacturer or development engineers is much easier.

After completion of the survey and proper data processing, the requirements of the customers were classified into four categories according to their similarities and then broken down to a lower level. The characteristics that influence the development of the new handle can be classified according to Functionality (vertical positioning of the handle, opening with pulling the handle to the right, the middle length of the handle, etc.) and Aesthetic appearance (somewhat rounded shape, aluminum material, monochrome and door-compatible color, etc.). Other factors (price, safety, easy opening, environmental impact, etc.) and After-sales factors (service and warranty, possibility of replacing decor, recyclability) were not included in the survey, because most of them are necessary for the development of a new product and require high ratings; regardless, they were included in the House of Quality.

Since all customer requirements are not equally significant, it is crucial to evaluate them, to determine the importance of what was achieved by survey and statistical processing (the average estimates from statistical processing for the whole group of respondents are entered). For other and after-sales factors that were not included in the survey, the estimates were made jointly with engineers. Engineers, with the help of customer ratings, get a good insight into the features that are crucial in the development process (Table 3).

Table 3. Customer requirements and evaluation.

\begin{tabular}{cc}
\hline Functionality & Evaluation \\
\hline Vertical handle installation & 3.3 \\
Operation in the right direction of opening & 3.5 \\
Medium length of handles & 3.1 \\
Suitable hand access to handles & 3.6 \\
Slightly sliding grip 3.2 & 3.2 \\
Grip in several places of the handles & 3.1 \\
\hline Aesthetic Appearance & \\
\hline Slightly curved shape 3.4 & 3.4 \\
Aluminum handle & 3.2 \\
Color matching the fridge door and one-color handle & 2.9 \\
Inserted logo or inscription & 1.6 \\
\hline Other Factors & \\
\hline Price & 5 \\
Security & 5 \\
Easy opening & 5 \\
Impact on the environment & 4 \\
Durability and reliability & 5 \\
\hline After-Sales Factors & \\
\hline Service and warranty & 3 \\
Changeable decors & 3 \\
Recyclability &
\end{tabular}

\section{Discussion}

As stated in many previous studies (conducted by References [23,24], etc.), it is of crucial importance to include potential customers in to the new product development process from its initial phases. In our research, we emphasized the same approach because open innovation collaboration could only produce good results if all the stakeholders communicate from the start of the process [54]. During the construction of the House of Quality, we managed to get the information important for the development of the new handle, especially the insight into the customer's choices. In accordance with 
the customer's requirements the new grip should be vertically attached to the door and of medium length. An important finding was the different choice of respondents for the direction of operation of the handle when opening, which according to statistical tests did not occur randomly, so the handle of the symmetrical version with the possibility of attachment on the left or the right side of the door will provide a pull in the buyer's desired direction.

The constructor must pay great attention to determining the appropriate distance between the door and the handle, as this feature was seen by the respondents as the most important one. It was surprising that respondents did not want an inscription or logo on the handle, so they should not be added to the handle. We estimate that the refrigerator with a new handle fitted will be better sold if sellers emphasize its purpose.

The respondents with a high average value of 4.363 estimated that the knowledge of the customer's needs and requirements by the product manufacturers is very important, which confirms the reference to the publications and should also apply to the principle in the future; regardless of the product and the company that develops it.

Depending on age and gender groups, there were also differences in the choice of some features (e.g., grip handles), which were also not random.

\section{Conclusions}

It is reasonable to include the customer into the development starting with brainstorming phase and in the continuation at different stages of the product development. This avoids possible problems mainly associated with costs. The key to successful cooperation is also team work and the combination of ideas. Therefore, nowadays the Open Innovation Concept where buyers, suppliers and users are invited to participate in the collection of ideas is increasingly being implemented. This promotes creativity that can lead to great ideas that ultimately give added value to the product. The group work also creates the enjoyable social environment for people. The development of quality functions is an important factor in the development of the product itself, because it is based on the success of the product. Each product is produced in order to serve a purpose and satisfy the customer's needs. It is very important to satisfy the customer's needs in the first place, as well as to make technical improvements. As with the previous assumption, team work is also very important here. We meet the needs of customers using different methods. Every method of obtaining data is useful on its own, and we need to adapt it to a given situation. Most authors, as the most effective method, refer to the focus group as it provides an overall and high-quality view of the whole issue, but it is associated with high costs.

Our research was limited to a national context and it did not capture the complete range of all potential buyers of household appliances (focusing on a single functionality aspect, not covering different income levels of customers, etc.). However, it shed a light on the fact that it is necessary to include customers in a given product development. This contributes to the fact that a manufacturer can expect a sustainable relation with its customers only if their needs and requirements are carefully met. The following are the decision-making processes that play a very important role in obtaining information. Not every process of collecting information is suitable for each group of people. Therefore, it is necessary to make precise analysis on what types of customers we are dealing with and that could be one of the main aspects of future research direction. One should take into account that there are differences between manufacturing and service companies when creating a new product [55]. The last thing to know, however, is the House of Quality as the basic diagram of compiling needs. Each product is built according to a specific procedure. The key to success is well coordinated teamwork, and deep understanding of the customer's wishes and needs. With the hierarchy of needs, we have a comprehensive overview of what the customer wants and what we are able to do on our own. This eliminates too many discrepancies between wishes and possible solutions.

Summarizing the QFD Method, we can say that it certainly improves product quality planning, enables better organization and mutual cooperation and reduces the required development time. 
If surveys are well formulated in the phase of obtaining information about the wishes of our customers, this certainly reduces the changes and costs in the development process. However, there is always the possibility that the respondents from the questionnaire do not fully represent the difference, for example, between steel and aluminum or other relevant data that we are looking for. It is therefore sensible to offer potential buyers some types of prototypes, and that way give them the choice based on "grip" and realistic judgment. The original contribution of this paper is reflected in the integration of the CA and QFD methods with users at an early stage in the development of a new product. Certainly, the improvement of the proposed process can be expected after the finalization of the product and its placement on the market. On the other hand, it would be interesting to test in future research the creation of a conceptual equation modeling approach, by using for example the model given in the work of Spanos and Lioukas [56]. Customers in today's world are becoming increasingly informed, educated, demanding. They always want to get the highest possible quality at the lowest possible price. At the same time, the third industrial revolution has already started, and on the arrival of Industry 4.0, it is oriented towards individualized product development, as individual treatment of individual buyers. Strategies should therefore be devised for the installation of alternative sources of energy in the vicinity of the company, the strategy of perfectly managing business processes due to constant changes in the political, business and social environment and, above all, close to the customers in order to provide the product with a quick delivery. Determining the wishes and needs of customers using different methods will play a vital role in providing quality products and good sales companies. In this respect, results of our paper highlight the importance of a modern approach while designing and determining main functions of a new product. Such an approach includes active integration of consumers in the process of new product development through a VOC - a very powerful tool in innovation and marketing activities. The presented approach could be used for both new product development and modification of an existing product in any given industry.

Author Contributions: Conceptualization, M.L.; Formal analysis, J.B. and M.R.; Methodology, A.I.; Project administration, J.B. and M.R.; Resources, M.R.; Supervision, M.L. and B.Ś.; Validation, B.Ś.; Visualization, J.B.; Writing—original draft, M.L. and A.I.; Writing—review \& editing, J.B., M.R. and B.Ś.

Funding: This research was funded by the Ministry of Education, Science and Technological Development of the Republic of Serbia, grant number 47005 and the APC was partially funded by grant number 47005 .

Acknowledgments: The authors acknowledge the financial support of the Ministry of Education, Science anWd Technological Development of the Republic of Serbia, within Project No 47005.

Conflicts of Interest: The authors declare no conflicts of interest.

\section{References}

1. Rehar, T.; Ogrizek, B.; Leber, M.; Pisnik, A.; Buchmeister, B. Product lifecycle forecasting using system's indicators. Int. J. Simulat. Model. 2017, 16, 45-57. [CrossRef]

2. Trott, P. Innovation Management and New Product Development, 4th ed; Financial Times Prentice Hall: Harlow, UK, 2008.

3. De Sousa Jabbour, A.B.L.; Jabbour, C.J.C.; Foropon, C.; Godinho Filho, M. When titans meet—Can industry 4.0 revolutionize the environmentally-sustainable manufacturing wave? The role of critical success factors. Technol. Forecast. Soc. Chang. 2018, 132, 18-25. [CrossRef]

4. Lee, M.H.; Yun, J.H.J.; Pyka, A.; Won, D.; Kodama, F.; Schiuma, G.; Park, H.; Jeon, J.; Park, K.; Jung, K.; et al. How to respond to the Fourth Industrial Revolution, or the Second Information Technology Revolution? Dynamic new combinations between technology, market, and society through open innovation. J. Open Innov. Technol. Mark. Complex 2018, 4, 21. [CrossRef]

5. Pachura, A. Innovation and change in networked reality. Pol. J. Manag. Stud. 2017, 15, 173-182. [CrossRef]

6. Preston, M. Business Success beyond the Short Term: CEO perspectives on Sustainability. PwC 17th Annual Global CEO Survey: Sustainability, 2014. Available online: https://www.pwc.com/gx/en/sustainability/ ceo-views/assets / pwc-ceo-summary-sustainability.pdf (accessed on 22 January 2017). 
7. Dangelico, R.M.; Pontrandolfo, P.; Pujari, D. Developing sustainable new products in the textile and upholstered furniture industries: Role of external integrative capabilities. J. Prod. Innov. Manag. 2013, 30, 642-658. [CrossRef]

8. Wittink, D.R.; Cattin, P. Commercial use of conjoint analysis: An update. J. Mark. 1989, 53, 91-96. [CrossRef]

9. Kanda, N. The seven product planning tools for new product development. Hinshitsu Kanri 1994, 45, 73-80.

10. Gustafsson, A.; Ekdahl, F.; Bergman, B. Conjoint analysis: A useful tool in the design process. Total Qual. Manag. 1999, 10, 327-343. [CrossRef]

11. Pullman, M.E.; Moore, W.L.; Wardell, D.G. A comparison of quality function deployment and conjoint analysis in new product design. J. Prod. Innov. Manag. 2002, 19, 354-364. [CrossRef]

12. Chai, K.H.; Xin, Y. The application of new product development tools in industry: The case of Singapore. IEEE Trans. Eng. Manag. 2006, 53, 543-554. [CrossRef]

13. Kotler, P. Marketing Management_Trženjsko Upravljanje: Analiza, Načrtovanje, Izvajanje in Nadzor; Slovenska knjiga: Ljubljana, Slovenia, 1998.

14. Vedenik, G.; Leber, M. Change management with the aid of a generic model for restructuring business processes. Int. J. Simul. Model. 2015, 14, 584-595. [CrossRef]

15. Joueid, A.; Coenders, G. Marketing innovation and new product portfolios. A compositional approach. J. Open Innov. Technol. Mark. Complex 2018, 4, 19. [CrossRef]

16. Shpak, N.; Satalkina, L.; Sroka, W.; Hittmar, S. The social direction of enterprises' innovation activity. Pol. J. Manag. Stud. 2017, 16, 187-201. [CrossRef]

17. Hauc, A. Projektni Management: Strokovna Monografija; GV Založba: Ljubljana, Slovenia, 2007.

18. Mahmud, M.; Aryanto, V.D.W.; Hasyim, H. The effect of innovation capability and new product development on marketing performance of batik SMEs. Pol. J. Manag. Stud. 2017, 15, 132-141. [CrossRef]

19. Vveinhardt, J.; Kuklytè, J. Development improvement programme of social business models in Lithuania. Forum Sci. Oeconomia 2016, 4, 149-170.

20. Atuahene-Gima, K.; Murray, J.Y. Exploratory and exploitative learning in new product development: A social capital perspective on new technology ventures in China. J. Int. Mark. 2007, 15, 1-29. [CrossRef]

21. Cooper, R.G. Winning at New Products: Accelerating the Process from Idea to Launch; Perseus Books Group Publishing: New York, NY, USA, 2001.

22. Cooper, R.G. Winning at New Products: Creating Value through Innovation; Perseus Books Group Publishing: New York, NY, USA, 2011.

23. Cooper, R.G. Winning at New Products, 2nd ed.; MA: Perseus Books Group Publishing: New York, NY, USA, 1993.

24. Gruner, K.E.; Homburg, C. Does customer interaction enhance new product success? J. Bus. Res. 1998, 49, 1-14. [CrossRef]

25. Sawhney, M.; Verona, G.; Prandelli, E. Collaborating to compete: The Internet as a platform for customer engagement in product innovation. J. Interact. Mark. 2005, 19, 4-17. [CrossRef]

26. Grewal, R.; Lilien, G.L.; Mallapragada, G. Location, location, location: How network embeddedness affects project success in open source systems. Manag. Sci. 2006, 52, 1043-1056. [CrossRef]

27. Jeppesen, L.B.; Molin, M.J. Consumers as co-developers: Learning and innovation outside the firm. Tech. Anal. Strat. Manag. 2003, 15, 363-383. [CrossRef]

28. Gojkovič, M.; Weber, C.; Adam, F.; Leber, M. Mobile application as an innovative supply chain concept and the impact of social capital. Int. J. Simulat. Model. 2014, 13, 135-146.

29. Prahalad, C.K.; Ramaswamy, V. Co-Creation experiences: The next practice in value creation. J. Interact. Mark. 2004, 18, 5-14. [CrossRef]

30. Bowers, M.R.; Martin, C.L.; Luker, A. Trading places: Employees as customers, customers as employees. J. Serv. Mark. 1990, 4, 55-69. [CrossRef]

31. Ghapanchi, A.H.; Tavana, M. A longitudinal study of the impact of open source software project characteristics on positive outcomes. Inform. Syst. Manag. 2015, 32, 285-298. [CrossRef]

32. Fang, E. Customer participation and the trade-off between new product innovativeness and speed to market. J. Mark. 2008, 72, 90-104. [CrossRef]

33. Franke, N.; Von Hippel, E.; Schreier, M. Finding commercially attractive user innovations: A test of lead-user theory. J. Prod. Innov. Manag. 2006, 23, 301-315. [CrossRef]

34. Franke, N.; Keinz, P.; Steger, C.J. Testing the value of customization: When do customers really prefer products tailored to their preferences? J. Mark. 2009, 73, 103-121. [CrossRef] 
35. Dabholkar, P.A. How to improve perceived service quality by improving customer participation. In Proceedings of the 1990 Academy of Marketing Science (AMS) Annual Conference; Dunlap, B.J., Ed.; Springer: Cham, Switzerland, 2015; pp. 483-487.

36. Pitt, L.F. The penguin's window: Corporate brands from an open source perspective. J. Acad. Mark. Sci. 2006, 34, 115-127. [CrossRef]

37. Etgar, M. A descriptive model of the consumer co-production process. J. Acad. Mark. Sci. 2008, 36, 97-108. [CrossRef]

38. Bendapudi, N.; Leone, R.P. Psychological implications of customer participation in co-production. J. Mark. 2003, 67, 14-28. [CrossRef]

39. Cook, S. The contribution revolution. Harv. Bus. Rev. 2008, 86, 60-69.

40. Sawtooth Software. Choice Based Conjoint, Svetovni Splet. Available online: http://www.sawtoothsoftware. com/products/cbc/cbc_method (accessed on 10 August 2016).

41. Bastič, M. Izbrana Poglavja iz Kvantitativnih Metod v Raziskavitrga: Učno Gradivo; Fakulteta za logistiko: Celje, Slovenia, 2006; pp. 9-16.

42. Polajnar, A.; Buchmeister, B.; Leber, M. Proizvodni Menedžment: Učbenik; Fakulteta za logistiko: Maribor, Slovenia, 2001; pp. 97-115.

43. Roman, E. Voice-of-the-Customer Marketing: A Revolutionary Five-Step Process to Create Customers Who Care, Spend, and Stay; McGraw-Hill: New York, NY, USA, 2011.

44. Higgins, J.P.T.; Green, S. (Eds.) Cochrane Handbook for Systematic Reviews of Interventions 4.2.6 [Updated September 2006]. Available online: http://www.cochrane.org/resources/handbook/hbook.htm (accessed on 10 January 2017).

45. Newton, P. Interview Questions, Career Skills. Available online: https://openlibrary.org/books/ OL25902230M/Interview_Questions_Career_Skills (accessed on 28 January 2017).

46. Rosseel, Y. Lavaan: An R package for structural equation modeling. J. Stat. Softw. 2012, 48, 1-36. [CrossRef]

47. Team, R.C. R: A Language and Environment for Statistical Computing; R Foundation for Statistical Computing: Vienna, Austria, 2014; Available online: https:/ / www.R-project.org/ (accessed on 20 January 2017).

48. Flora, D.; Curran, P. An empirical evaluation of alternative methods of estimation for confirmatory factor analysis with ordinal data. Psychol. Meth. 2004, 9, 466-491. [CrossRef] [PubMed]

49. Hu, L.; Bentler, P.M. Cutoff criteria for fit indexes in covariance structure analysis: Conventional criteria versus new alternatives. Struct. Equ. Model. Multidiscip. J. 1999, 6, 1-55. [CrossRef]

50. DiStefano, C.; Liu, J.; Jiang, N.; Shi, D. Examination of the weighted root mean square residual: Evidence for trustworthiness? Struct. Equ. Model. Multidiscip. J. 2017, 25, 453-466. [CrossRef]

51. Tavakol, M.; Dennick, R. Making sense of Cronbach's alpha. Int. J. Med. Educ. 2011, 2, 53-55. [CrossRef] [PubMed]

52. Ivanisevic, A.; Katic, I.; Buchmeister, B.; Leber, M. Business plan feedback for cost effective business processes. Adv. Prod. Eng. Manag. 2016, 11, 173-182. [CrossRef]

53. Sroka, W. Problem of organizational learning in strategic alliances. J. Inform. Contr. Manag. Syst. 2011, 9, 51-66.

54. Dudzevičiūtè, G.; Tvaronavičienè, M. Measurement framework of innovation activity: Theoretical approaches' analysis. J. Secur. Sustain. Issues 2011, 1, 63-75. [CrossRef]

55. Borocki, J.; Radišić, M.; Štefanić, I. Space analysis as a tool for internal development factors measurement within companies. Tech. Gazzete 2018, 25 (Suppl. 2), in press.

56. Spanos, Y.E.; Lioukas, S. An examination into the causal logic of rent generation: Contrasting Porter's competitive strategy framework and the resource-based perspective. Strat. Manag. J. 2001, 22, 907-934. [CrossRef]

(C) 2018 by the authors. Licensee MDPI, Basel, Switzerland. This article is an open access article distributed under the terms and conditions of the Creative Commons Attribution (CC BY) license (http:/ / creativecommons.org/licenses/by/4.0/). 